\title{
Clarifying the best interests standard: The elaborative and enumerative strategies in public policy-making
}

\author{
Chong Ming Lim \\ Michael Dunn \\ Jacqueline Chin
}

\begin{abstract}
INTRODUCTION
One recurring criticism of applying the best interests standard to making decisions on behalf of incompetent individuals lacking the capacities to make their own decisions, concerns its vagueness and thus the inadequate guidance it offers to care providers. The criticism is motivated by two sets of concerns. First, the considerations regarded as salient for best interests decisions are not uniform across different cases of incompetence. For example, the best interests of formerly competent adults involve different considerations from the best interests of those who have never been competent to make decisions - such as the profoundly mentally disabled. Not only do these individuals lack the capacities for autonomous choice, their values and preferences - if they have any - are either opaque or admit too much room for interpretation or ascription, and thus neither definitively nor adequately guide decisions made on their behalf.[1-2] The considerations are distinct, again, for those whose decision-making capacities are not-yet fully developed, such as very young children. They vary further as these minors approach 'Gillick competence' the weight of their views and autonomous choices increase.[3] The lack of an agreed definition of 'best interests', together with the fact that several suggested considerations adopted in legislation or professional guidelines for care providers do not obviously apply uniformly across different individuals, result in decisions being made in murky waters - potentially (viciously) intuitionistic in character, and lacking a clear justification. Second, the best interests standard is specified in legislation (at least in England, Wales, and Singapore) by a list of 'best interest considerations' that are seemingly merely enumerated, without further guidance as to how those considerations are to be weighed. The lack of a decision procedure invites the charge that the standard is unhelpful in guiding decision-making. For many care providers, sorting and weighing the myriad relevant considerations for incompetent patients are exercises in indeterminacy and frustration. $[2,4]^{1}$
\end{abstract}

Partly in response, bioethicists have attempted to specify the best interests standard, to reduce the indeterminacy surrounding surrogate decisions.[5-7, among many others] In this paper, we discuss the bioethicists' responses specifically in relation to the state's role in clarifying the best interests standard. There are two related motivations for discussing the clarification of the best interests standard in relation to the state. The first stems from the

\footnotetext{
${ }^{1}$ In this paper, we leave aside difficulties pertaining to understanding what counts as 'best' (i.e. the "metaphysics", as it were, of "best”).
} 
recognition that implicit within clarifications of the standard is the assumption and intention that it applies generally, to all best interests decisions. The most natural domain to situate the general conclusions presented by bioethicists is in the sphere of regulatory interventions executed by the state. The second is that legislation has already been framed in terms of the best interests standard, such as the Mental Capacity Act 2005 of England and Wales, and Singapore's Mental Capacity Act 2008 - thus the need to critically discuss how the standard ought to be specified by the relevant states.

Before we begin: two quick notes concerning the focus of our paper. First, despite the narrow initial motivations, our arguments are not constrained to only policy decisions in those countries in which regulations invoke this concept explicitly. Insofar as the problem which the best interests standard seeks to address occurs more generally across different national jurisdictions and decision-making contexts, our arguments are likewise generalisable. Second, our arguments have been formulated with the case of incompetent adults in sight. While we believe that the general argumentative structure may be extended to the context of parents making decisions on behalf of children, we do not undertake such an extension in this paper. In this paper, we leave open the possibility that the different set of relevant considerations in the latter case may render the extension implausible.

In the first section, with the use of several brief examples we identify and characterise two clarificatory strategies employed by bioethicists - elaborative and enumerative. Then, we argue that the latter strategy is more defensible in pluralistic societies - in which citizens affirm different and often competing comprehensive conceptions of the good. Beyond the practical difficulties of applying the former strategy, its adoption by the state would be prejudicial in a pluralistic society - directing our attention to some moral considerations while blinding us to others. Given the gravity of best interests decisions, and the delicate task of respecting citizens' different conceptions of the good (which shape their understanding of best interests), only the enumerative strategy is viable. To assuage worry, we argue that this strategy does not immediately or obviously commit the state to silence in providing guidance to and supporting care providers, nor does it facilitate or permit the abuse of the vulnerable. In the third section, we address two methodological worries about adopting this strategy at the state level, showing that the enumerative strategy neither adopts a defeatist attitude, nor does it eventually collapse into (a form of) the elaborative strategy.

\section{TWO CLARIFICATORY STRATEGIES}

The core question which the best interests standard attempts to address is: how do we decide for those who cannot decide for themselves? ${ }^{2}$ However, the response - 'in the best interests of the patient' - is inadequate both in specification, and the guidance it offers to those who have to decide. In what follows, we discuss two main strategies - the elaborative and enumerative which bioethicists have taken in clarifying the best interests standard. A

\footnotetext{
${ }^{2}$ We set aside other strategies addressing this question, including the substituted-judgement standard. Crucially, we are not committed to the benefits and trade-offs between different strategies to this core question.
}

Comment [m1]: Typo I think there that I've corrected 
qualification: these strategies do not constitute separate "camps" to which theorists pledge their allegiances to the exclusion of the other. In reality, most bioethical and legal work incorporate elements of both clarificatory strategies without fanfare. Looking to actual best interests decisions reveals the same. However, the elaborative and enumerative strategies are nevertheless two distinct approaches which have been taken while clarifying the best interests standard. ${ }^{3}$ Specifically, their main difference lies in how they address the 'inescapable perplexity, ambiguity, ignorance, uncertainty, and conflict'[8] in weighing factors as varied as 'physical and mental suffering, chances of recovery, the nature of the patients' interactions with his or her environment, the potential for a regaining of function, and indignity' (at 104).[9] As will become clearer later, this distinction is important once we consider the question of which strategy the state may viably adopt.

The first strategy - which we term the 'elaborative strategy' - attempts clarification of the standard through elaborating on the substantive content or bases of the standard. It is motivated by the conception that analyses of what is meant (implied or entailed) by the considerations within the standard, and how those are grounded in more fundamental terms - perhaps via appeals to more general or overarching principles - will clarify the standard. In practice, this is often done via establishing the normative weight of one (or more) of the myriad considerations, over all others, involved in making surrogate decisions for incompetent individuals. Most theorists are wary not to make blanket proclamations that a selected consideration always trumps others regardless of context. Instead, they take to identifying certain scenarios in which that consideration outweighs the rest - thus leading to (or in some cases, mandating) a specific decision. Guidance for other cases can then be worked out, as it were, through tracking their differences from these "paradigm" cases in which the correct decisions are clear or obvious. If (and when) agreement is reached in specific scenarios, the extent of the indeterminacy which plagues best interests decisions is reduced. From there, as more agreement is garnered, common themes or values may gradually emerge - which may then be used to further clarify future decisions and correct earlier mistakes. However, there is no consensus. Various authors disagree about how much weight to assign to different considerations in similar scenarios, and few (if any) commitments are made about decisions beyond those scenarios.

One notable instance of this strategy is found in Norman Cantor's discussions of intrinsic human dignity. From his analyses of the values embedded (implicitly or explicitly) in the public sphere - including constitutional jurisprudence (at 118-119),[9] and majority opinion (at 121-125)[9] - Cantor proposes that the idea of intrinsic human dignity should feature as the crucial consideration in best interests decisions. Intrinsic human dignity refers to the 'basic respect to which every human being is entitled, regardless of cognitive capacity', and serves as an 'ultimate constraint' on the ways we can treat each other. An integral part of this consists in freedom from degrading treatment -

\footnotetext{
${ }^{3}$ While we do not argue for it in our paper, our clarifications of the strategies indirectly reveal unresolved tensions in recent discussions about best interests, especially those relating to how the best interests standard should be clarified in law).
} 
applicable even where a patient may be incognisant or dying (at 30, 117).[9] According to Cantor, this dignity is violated in cases of permanent unconsciousness - in which the patient is unable to relate to and interact with others or the environment, nor experience any of the pleasures (and presumably pains) associated with human existence (at 122), and in which the patient is reduced to a 'passive object of bodily invasions and manipulations' (at 39).[8] In this way, permanent unconsciousness stands out as one circumstance which is 'so intrinsically demeaning that the dignity interest alone ... would justify removal of life support' (at 122, our emphasis).[9] This is the specific clarificatory payoff: in this specific scenario, there is no indeterminacy. All other considerations are outweighed, and we are directed to the correct answer by the dignity "trump-card". So, doggedly preserving life violates the intrinsic human dignity of the patient, whereas being allowed to die is respectful of it - a claim applicable even if the patient cannot experience the degrading nature of his or her situation. This sees Cantor making the policy recommendation that the removal of life support from a permanently unconscious patient be mandatory (at 127).[9]

Beyond Cantor, other values have been posited as having considerable weight in other circumstances - such as avoiding extreme and unremitting suffering,[10] or the importance of continuing life.[11]

The second strategy attempts clarification via enumerating the (kinds of) considerations relevant to best interests decisions. Unlike the former, no substantive elaboration or specification of the considerations are proffered. Commitment concerning the considerations is kept to an absolute minimum, if not entirely eliminated. For instance, the UK Mental Capacity Act 2005 and Singapore Mental Capacity Act 2008 may be partly construed as adopting a position in line with the enumerative strategy - just insofar as they do not define what counts as best interests. ${ }^{4}$ Additionally, the Codes of Practice accompanying the Acts restrict themselves to only listing what they identify as relevant considerations, without further elaboration or guidance on their weight relative to each other, or how they are to be sorted out.[12-15] The orienting idea consists in identifying all relevant considerations from different perspectives, before any decision is made. While laborious, this strategy mitigates against the hastiness that sometimes distorts reasoning under intense pressure.

As we see it, the relevant considerations may be identified in at least two ways. Considerations may be identified by examining how different comprehensive religious, moral and philosophical doctrines ('comprehensive doctrines') address the issue of best interests. Comprehensive doctrines cover most, if not all, aspects of human life. While some of these doctrines are religious in nature, religiosity is not an essential aspect. Crucially, comprehensive doctrines contain ideals of the good, and of what is valuable in human life. These may include human beings' relationships with their families, associates, environment, as well as their place in the universe writ large.[16] Examining

\footnotetext{
${ }^{4}$ We say "partly", because in the application of the best interests standard, the UK Court of Protection has provided some elaboration of the principles it applies, and commensurates between them. See Reference [11].
} 
these comprehensive doctrines in detail therefore reveals the considerations that those who are committed to them deem relevant in making decisions about their lives - including best interests decisions. It is in light of this, that David Degrazia outlines and contrasts the implications concerning best interests that different doctrines are committed - noting that '[greater] awareness of the theoretical issues, of plausible options, and of the implications of each leading option is likely to enhance the integrity of future efforts to unpack the concept of a patient's best interests'.[17] Unfortunately, inadequate attention has been directed to such explorations - one notable exception being discussions of the best interests of children.[18]

The second way of identifying relevant considerations lies in being attentive to the details and particularities of specific cases. This may reveal additional relevant considerations which may not be easily captured via simply theorising about comprehensive doctrines. Recently, Tony Hope and his colleagues have highlighted several additional considerations that should feature in best interests deliberations, after examining the specific features of the case of dementia. They argue that factors such as the present values and wishes of the patient, and their weight relative to other considerations depending on the strength with which they are held, are relevant considerations. Thus they reject the simplistic notion that dementia patients' current preferences can be discounted, or easily outweighed by past ones, or do not even feature in best interest decisions.[19] This is echoed by Jennifer Hawkins, who argues that the best interests of an individual with dementia changes corresponding to how she (and her views) changes.[20] Andrea Fenwick, considering the cases of patients in persistent vegetative states, argues that we need to carefully formulate what considerations are in fact at play - rather than over-readily extend decisions from other best interests cases to them.[21]

While the characterisations of both strategies are brief, the salient difference between them is already clear. The elaborative strategy attempts clarification of the best interests standard by developing - elaborating - the substantive content of the concept of best interests. This elaboration constitutes a view of what best interests really mean, which is intended to provide guidance for how we ought to apply it. On the other hand, the enumerative strategy restricts itself to listing, or enumerating, the various considerations relevant to making such decisions. No additional account is provided on how these considerations weigh up against each other. Additionally, no view of, or commitment about, the meaning of the concept 'best interest' is adopted. This brief characterisation is sufficient for us to move forward with our discussions.

\section{WHICH STRATEGY FOR THE STATE?}

Which strategy should the state adopt in clarifying the best interests standard? If it adopts the latter, enumerative strategy - as seems to be the case in the aforementioned Mental Capacity Acts - it appears vulnerable to (at least) three important criticisms. The first is that the enumeration of considerations is not accompanied by any guidance on how they weigh up against each other. From the perspective of care workers obliged to apply the standard, the enumerative strategy does not even count as a clarificatory strategy - it is simply a list. Best interests decisions are still likely to be made in murky waters - intuitionistic, 
and possibly poorly approximating what is truly best for the patients. The second, related, criticism is that this failure to provide adequate guidance constitutes, in effect, a failure of law. Richard Huxtable argues that there are important criteria - pertaining to consistency and action-guidance - which a system of law must meet in order to be effective. Insofar as the enumerative strategy fails to provide guidance, it also appears unable to ensure consistency across different cases in which the application of the best interests standard is required (at 11-31).[22]. The state should try to avoid this unpalatable conclusion, by rejecting the enumerative strategy. The third, related, criticism is that the enumerative strategy appears to leave too much room for the abuse of vulnerable patients. Without a clear system of weighing considerations, those beyond the patients' direct interests - such as resource limitations, parental or third-party interests - may enter while masquerading as being in their best interests.[23-24] However, it is our contention that these criticisms are not decisive against the enumerative strategy, and moreover that they are not as serious as those arising from the state's possible adoption of the elaborative strategy. We address these criticisms at various points throughout the paper.

We begin by rejecting the state's adoption of the elaborative strategy. The motivation for our rejection lies in taking seriously the extent and depth of citizens' disagreements about ideals of what is good or valuable in human life. These disagreements stem from their different comprehensive religious, moral and philosophical doctrines. In pluralistic societies - as UK and Singapore both are - these disagreements are likely to be fundamental, and pervasive. From the perspective of each citizen, from his or her comprehensive doctrines, the practices of others are likely to be regarded as at best alien, or at worst fundamentally misguided about the source and manifestation of human value. It is in such a context that the state's adoption of the elaborative strategy faces serious problems.

In elaborating the best interests standard substantively in any particular way, the state fails to respect the plurality of comprehensive doctrines among its citizens, and does not succeed in being neutral among them. Different doctrines' views of best interests differ pursuant to their interpretations of the relevant considerations and the weight attached to them.[17] A religious doctrine which values continued life would differ sharply in its determination of best interests, from a philosophical doctrine prioritising rational thought and autonomy - a difference which perhaps frequently shows up in people's sharply opposing positions on whether they would have a life worth living if they had progressively-worsening dementia. Yet if the state takes an elaborative stance on best interests, some citizens may be precluded from acting in accordance with their deeply-held convictions. From their perspectives, the state prejudicially and illegitimately employs its coercive powers to deprive them from realising values of central importance to their lives. ${ }^{5}$

\footnotetext{
${ }^{5}$ The question may be posed: could these citizens just be morally wrong? Our response is in the form of another question: 'from which perspective?' Except in gross cases of abuse, the "thin" commitments of a liberal state in a pluralistic society are insufficient to ground the fullfledged diagnoses of moral error which the initial question appears to make. In any case, our
} 
A tangential qualification needs to be entered. It may seem as though the talk of respecting plural comprehensive doctrines is inapplicable to best interests decisions - insofar as these decisions are made for incompetent patients who cannot (or may never be able to) uphold their commitments to their comprehensive doctrines, and who may not even have them in the first place. Two brief responses are available.

First, insofar as formerly-competent patients have commitments to comprehensive doctrines, there is a need to respect these commitments. While they are unable to uphold or put their commitments into practice, we nevertheless regard them as relevant considerations which need to be accounted for in any decisions concerning their best interests. This is pertinent not only for those who may regain competence, but also those who may never regain it. Ordinarily, we hold in high regard the shape and trajectory which individuals wish their lives to have. This involves us taking seriously their commitments - including their wishes and values - even in cases of incompetence. This explains why we even judge there to be a moral problem when, for instance, a Muslim dementia patient attempts to eat pork.[19] While these are admittedly intuitions, they are nevertheless sufficiently central to our moral judgements and practices such that they cannot be easily dismissed by merely citing the fact that incompetent patients have no existent commitments to their comprehensive doctrines which they are able to comprehend or uphold. ${ }^{6}$

Second, the worry appears stronger in the case of patients who have never been competent. As earlier mentioned, these individuals lack the capacities for autonomous choice, and along with them the capacities to comprehend or affirm any particular comprehensive doctrines. Their values and preferences if they have any - are opaque or admit too much room for interpretation or ascription. However, in these cases our attention should be drawn to the fact that even never-competent patients exist in moral communities with their families, who do have commitments to comprehensive doctrines. Of course, this does not mean that only the considerations pertaining to the latter are relevant. Yet we must still ensure that best interests decisions about nevercompetent patients are arrived at in a way that are at least consistent with the comprehensive doctrines of their family members. These are not empty moral considerations. Moreover, these decisions also may have corresponding impact on the well-being (broadly construed) of the patients. Thus, it is only in an impoverished sense that we may say of a decision that it is in the best interests of a patient, when it may lead to his or her exclusion or ostracism from the moral communities he or she exists in. ${ }^{7}$

point is that the state adoption of "thickly" specified commitments are prejudicial. We leave aside the separate difficulties arising from identifying and interpreting these "thin" commitments and their implications for public policy, and from comprehensive doctrines that violate even these "thin" commitments.

${ }^{6}$ In saying this, we are not therefore committed to any full-fledged preference- or desire-based account of best interests. Our point is merely that any commitment-based preferences or desires, if existent (even at some point), are relevant considerations to be taken seriously.

${ }^{7}$ Again, we are not committed to any full-fledged communitarian account of best interests.

The point is simply that these considerations have to be taken into account. Additionally, we 
We acknowledge that our remarks here are regrettably brief; however, arguing further for them will lead us too far astray. For readers unconvinced by these brief argumentative sketches, we implore that you tentatively grant us the minimal level of plausibility for locating our discussions of the best interests standard generally, in terms of respecting plural comprehensive doctrines. Otherwise, you may read our subsequent discussions concerning prejudice and illegitimacy as applying only to best interests decisions concerning formerlycompetent patients.

Returning to the main course: suppose the state adopts Cantor's position ${ }^{8}$ that intrinsic human dignity is violated in permanent consciousness, and that the removal of life support from a permanently unconscious patient is mandatory (at 127).[9] In doing so, the state adopts an elaborative approach to human dignity, committing to one meaning of dignity which is then used to constrain other actions involving dignity. Yet this is a very specific conception of dignity, amenable only to some comprehensive doctrines in some societies, while running counter to other conceptions implicit in other comprehensive doctrines and traditions. In effect, then, the state commits to a particular comprehensive account of human dignity (and best interests). What are the implications for citizens whose conceptions of intrinsic human dignity are different, and for whom continued life or struggle may be fundamental sources of value? It is insufficient, as Cantor concedes, that they be allowed the exception to sustain the lives of individuals lacking capacity (at 125).[9] This small consolation is diminished further in the face of two serious implications of the state's commitment to a particular comprehensive conception of human dignity.

First, citizens who want life support for their permanently unconscious wards have to expend their own resources to sustain them. ${ }^{9}$ This is not an alarmist worry, once we recognise the plurality of comprehensive doctrines and values in modern, pluralistic societies - which England, Wales, and Singapore are. From the perspective of those whose comprehensive doctrines do not happily coincide with the conception of dignity which the state adopts, their having to pay out of their own pockets in order to engage in practices important to them comes across as deeply unfair. This sense of unfairness is exacerbated in the case for those who lack resources to sustain their loved ones. They would have to relinquish being able to preserve the lives of their loved ones, with the knowledge that it is only because of the state's adoption of a substantively elaborated standard that they are unable to do so - and furthermore that it need not have been so, and it could have been otherwise.

side-step the rare cases where the never-competent patients have no family or dedicated carers, and thus cannot be said to be within any community. We thank an anonymous reviewer for highlighting this.

${ }^{8}$ While our arguments are focused on Cantor specifically, we take that they apply more generally to other instantiations of the elaborative strategy.

${ }_{9}^{9}$ Assuming that it is inconsistent for a state to make withdrawal of life support mandatory, and simultaneously fund continued life support for the exempted. 
Second, the commitment conveys the message that these citizens' conceptions of dignity (and along with them, the comprehensive doctrines around which their lives are centred) are not recognised as salient enough to feature in the formulation of public policy. This goes beyond the issue of resource distribution, and concerns the respect that the state fails to accord them in substantively elaborating on the conception of human dignity in a way which is inconsistent with, or that even precludes, theirs.

The state's adoption of the elaborative strategy is not helped by positing that the substantive elaboration of the best interests standard is tentative, expecting development to the point that it accommodates (or is at least compatible with) the different doctrines that citizens hold. Here, the hope may be that the standard would eventually be the object of something like John Rawls' overlapping consensus[16] - one which citizens of different convictions affirm, albeit for different reasons stemming from their comprehensive doctrines. Yet this expectation is unreasonable. It trivialises the extent of pluralism in societies today, and turns a blind eye to the intractable disagreements between citizens concerning what makes a life good or worth living.[25] It is not that it is difficult to find such a standard, but rather that it is implausible (or even impossible?) that it can be found. The state does not occupy an epistemically superior vantage point from which it may invent or chance upon such a standard. In pluralistic societies, there is no such vantage point which does not simultaneously discriminate against one or more of the comprehensive doctrines which citizens hold. It would be a grave mistake to conflate the authority of the state to arbitrate (via legislation) these best interests decisions - which it may have the political legitimacy to carry out - with the claim that such arbitrations are therefore morally unproblematic or legitimate for all citizens. ${ }^{10}$ Moreover, the question remains as to what happens in the interim before the state stumbles upon the substantive standard to fit all stripes. The discrimination and abuse which is dealt to those whose doctrines currently disagree with the state-endorsed elaborated standard is not justified by appealing to the possible existence of a future standard palatable to all - thus returning us to the earlier criticism.

Taken together, the state's adoption of the elaborative strategy to specify the best interests standard would achieve an artificial clarity about how to make best interests decisions, at the cost of according inadequate respect to the myriad of citizens' views concerning best interests. In order to avoid the earlier criticisms, the state should instead restrict itself to the enumerative strategy - resisting elaboration on any of the considerations relevant to best interests decisions, or how they should be weighed against each other. Only

\footnotetext{
${ }^{10}$ We agree with Richard Huxtable that compromise is likely the best solution we have, for cases of conflict concerning best interests, in the context of pluralism in current societies (at 123-141).[22] However, we are concerned that Huxtable's discussion of principled compromise may not fully account for the depth and extent of pluralism. Pluralism may run deeper than that concerning first-order normative commitments about best interests, and may also extend to judgements on what count as appropriate conditions and procedures for compromise. This is a matter the full resolution of which (partly) requires further empirical work, and which cannot be adequately addressed in this paper.
} 
through this can the state maintain its neutrality in the face of citizens' different comprehensive doctrines. ${ }^{11}$

Adopting the enumerative strategy does not commit the state to remaining silent on providing much-needed guidance to care providers. Guidance need not only be provided in specifying or elaborating on the law concerning best interests. To provide guidance, the state may fund empirical research into what considerations are deemed relevant for different communities, or for specific individuals.[26-27] Directed surveys may reveal important considerations for some minority communities, the salience of which may otherwise be diminished by general surveys across the population. For instance, Jehovah Witnesses' understanding of the considerations relevant to making best interests decisions may be "crowded out" when subsumed into a general survey seeking the majority or prevailing opinion on a particular issue. Specific information, on the other hand, can help care providers to make better decisions about their patients with different comprehensive doctrines, belonging to different ethnic or cultural groups. Repeating such investigations across different groups, the state arrives at a list of considerations that these groups deem morally important in making surrogate (or any medical) decisions. The enumeration of considerations is not done in an "a priori" fashion. However, the state should resist subsequently substantively elaborating the best interests standard to fit different communities, such that each community has a different yet substantively elaborated best interest standard applying to its members. The caution against adopting the elaborative strategy applies not only at the general level, but also at the level of specific communities. This is to allow for differences among members of the specific communities themselves - especially to those who incompletely or awkwardly belong to the communities, and deviate from common ideals and values. Even a "localised" elaborative strategy would still be unnecessarily restrictive.

Adopting the enumerative strategy also does not resign the state to allowing abuse of the vulnerable. It may prevent abuse by developing and mandating more comprehensive procedures for holding best interests discussion, and enforcing more stringent checks and balances. ${ }^{12}$ For instance, it may require that decisions are made together with a committee independent of the care providers. As suggested by Jeffrey Kirby, such a committee could include, among others, bioethicists, public representatives of the patients' comprehensive doctrines or traditions, family members, and all relevant care providers (and not just those directly providing medical care).[28] This echoes the suggestions of the Code of Practice for the Mental Capacity Acts, that there should be 'best interests conferences' that involve these participants (at 5.63-5.69).[14] Furthermore, it may be required of these discussions that they

\footnotetext{
${ }^{11}$ Is the gain in neutrality paid for by an irredeemable loss in certainty, consistency, or predictability? We develop our response to this in the final section, when we discuss the misplaced impulse for consistency in, and coordination of, best interests decisions across different cases.

${ }^{12}$ What counts as abuse will likely partly depend on the perspectives of the parties involved (seen from their comprehensive doctrines). We do not see this as leading to a kind of "freefor-all" situation where we are committed to silence on what counts as abuse - though we are unable to fully develop this idea here. Also see note 5 and its associated discussion.
} 
be thoroughly logged and made available to all the parties related to the patient. Settled decisions must then be made available on request to authorised auditors who review these decisions on a regular basis. The mere adoption of the enumerative strategy does not preclude the development and implementation of these processes. Of course, these committees may find themselves unable to come to a common resolution of their disagreements about patients' best interests, even after attempts at compromise. In such cases, the state may step in to temporarily and narrowly occupy the role as the final independent arbiter. ${ }^{13}$

Perhaps the worry about abuse may be rendered more specific, as arising in the context of cultural norms or practices which shape certain patients' best interests decisions in ways that we deem alien or unpalatable. Thus relativism rears its head. Does the state's respect for diversity and differences commit it to tolerate practices such as female genital mutilation? Without taking a stance on the raging debates, we instead contrast the case to that of existing accommodation of Jehovah's Witnesses' refusal of blood transfusion. In the latter case, after much campaigning by members of that religious community, there is now the recognition that what is in the best interests of the patients includes their comprehensive conceptions of the good, as well as their continued standing and integration with their moral and religious communities. They are not regarded as oddities irrelevant to best interests decisions. In fact, the Code of Practice for the UK Mental Capacity Act 2005 explicitly states that additional attention has to be paid to their views in making best interests decisions.[14] This accommodation, however, does not in practice fully extend to decisions concerning minors - especially in cases where a serious risk to life is present.[29-32] $]^{14}$ And even where such cases are eventually decided in opposition to the comprehensive doctrine views of the parents, there is now an increased sensitivity to the views of the parents, with a recognition to the potential community ostracism of those who receive blood transfusions. The conclusions we draw from this are practical - not only do decisions have to be made on a case-by-case basis, appeals to cultural or religious norms must be taken seriously regardless of how alien they may first seem, and finally that consultations with the communities more generally concerning their norms must be held in earnest to reach practical decisions. ${ }^{15}$ In this way, we take steps towards guarding against abuse which appears under the guise of differences in comprehensive doctrines. Of course, this does not fully resolve

\footnotetext{
${ }^{13}$ This is, in general terms, similar to the position advanced by Richard Huxtable (at 165182).[22] The crucial differences between our positions concern the role that the state (via law) should play in elaborating the best interests standard, and in the aim of such committees towards substantive consistency. On our account, there may be little progress towards consistency; the legitimacy of best interests decisions is also located, as it were, primarily in these committee decisions and negotiations between the relevant stake-holders. See our discussion in the final section, concerning the aspiration towards consistency in, and coordination of, best interests decisions.

${ }^{14}$ There are too many of such cases to list. For an explanation of the underlying motivation behind such an incomplete accommodation as understood by medical practitioners, see Reference [32].

${ }^{15}$ It appears that theoretical solutions to relativism generally must include these practical strategies, to ascertain the contents of conceptions we are relativistic about - though we will not argue for it.
} 
the threat of relativism, or specifically the problematic space left open for abuse by accommodating differences. But we must see clearly that these are choices we have to make, between the Scylla of disrespect and the Charybdis of possible abuse.

Finally, we note that the possible abuse of the vulnerable is not a problem intrinsic to the enumerative strategy (or its adoption) - but rather concerning whether due process has been carried out in its execution and enforcement. The point may be put another way: even if the state adopts an allencompassing and non-discriminatory elaborative standard of best interests (assuming it exists), abuse can still occur. There is no strict logical relation between adopting a particular position concerning the standard, and how it is implemented or enforced in particular decisions. It is not as though the mere adoption of the elaborative strategy precludes all possibilities of abuse. Like all institutions, the state and its courts are susceptible to error. If anything, the recent worries about the miscarriages of justice by the UK Court of Protection point to us just this fallibility in implementation.[33-34] As we have earlier indicated, mechanisms may be incorporated alongside the enumerative strategy to prevent abuse. We should not let considerations of process unduly confound our thoughts about which strategy the state should adopt.

\section{TWO METHODOLOGICAL WORRIES}

Two further worries arise about our proposal that the state adopts only the enumerative strategy. The first is that it takes a defeatist attitude towards reaching unified and unifying decisions in the face of pluralism. This worry may be expressed via an analogy to other terms which are purportedly as vague or unelaborated as 'best interests'. Norman Cantor, writing about the resistance to the idea of dignity as a common standard for surrogate decisionmaking, invites us to see the work that has been accomplished for the ideas of liberty or equality. Like dignity, the ideas of liberty or equality come across as vague, subjective and malleable - seemingly unsuitable as candidates for binding legal norms to guide decision-making. Additionally, different conceptions of liberty and equality exist, corresponding to differences in comprehensive doctrines. Yet this does not mean that 'the concept [of dignity] is fatally indeterminate or unusable as anything more than a grandiose yet impractical ideal' which cannot provide any guidance (at 9).[9] Cantor argues that even in a pluralistic society, there may be sufficient widespread understandings across communities and generations, which may help us to elaborate the meaning of dignity - citing how American jurisprudence has usefully embraced these ideas under the Fourteenth Amendment 'due process clause' and the 'equal protection clause' (at 9).[9] In our context, a similar argument may apparently be made about the idea of best interests. To refuse to elaborate the best interests standard, simply because there is currently disagreement about what best interests mean, thus appears to be defeatist in the same way as those who reject the use and elaboration of liberty and equality. In light of this, the state should put in even more work - perhaps doubling its efforts to find a substantively elaborated conception of best interests for all citizens - to ensuring that the elaborative strategy bears fruit, rather than abandoning it for the less-ambitious enumerative strategy. 
A clarification needs to be made about this argument by analogy - even if it succeeds, it does not address the criticism raised in the earlier section concerning the failure of the elaborative strategy to respect plural views. Consider the disagreements which still exist concerning the particular elaborations of liberty in American jurisprudence and legislation. That the elaborations have been useful in guiding institutions and practices does not mean that no more disagreements exist, nor that those elaborations do not at the same time exclude certain views from consideration. For instance, there are those who support elaborations of liberty which understand state regulations of working conditions and minimal wages as serious infringements on liberty; and others who view those regulations in precisely the opposite way - as precisely needed to protect the liberties of citizens.[35] A similar problem arises in the elaborations of the conception of human dignity. Take for instance Martha Nussbaum's notable attempt to defend a conception of human dignity for all citizens, partly in the form of a substantively elaborated list of capabilities central to human functioning or flourishing.[36-37] This capabilities approach has had important influence on political practices, and has been adopted by the United Nations Developmental Program as part of a global effort to fight poverty and illiteracy and to empower women.[38] Despite this, this approach has been criticised as illiberal and neo-colonialist because the narrow substantive conception of dignity that is put forward ends up either dismissing or disregarding other conceptions which do not cohere with it. In this way, Nussbaum's conception of dignity ends up paradoxically silencing those whom it seeks to protect.[39] ${ }^{16}$ In these situations, those who disagree are unlikely to be adequately persuaded simply by an appeal to the usefulness of the existing elaboration, or to the existence of widespread understandings. We contend that neither appeal is appropriate for the best interests standard. If anything, the impact of the state's adoption of a particular elaboration of the standard - precluding certain decisions or prejudicing against others, and directly determining the lives of one's ward (many times concerning issues of life and death) - is felt much more vividly and as involving higher (moral) stakes than abstract disagreements about liberty or dignity.

Moreover, cases where best interests decisions need to be made have one salient difference from the more general cases of liberty, equality or dignity. Discussions of the latter are often held in the context of constitutional essentials - concerning whether certain constitutional commitments are realised in practice.[16] The importance of such discussions lies partly in the fact that they concern the coordination of diverse individuals, as well as setting reasonable expectations for their social life with one another, from the perspective of society as a whole. Thus, there is obvious utility in specifying what exactly is meant by these terms - even if this utility obscures from our view the disagreements of the minorities. On the other hand, the requirement for social coordination and establishing expectations would be misplaced in the case of best interests decisions. The nature of best interests decisions is such that they arise only in specific situations which are highly personal and

\footnotetext{
${ }^{16}$ We leave open whether Nussbaum is indeed susceptible to this criticism. Our point is simply that substantive elaboration in the face of pluralism risks disrespecting citizens whose views differ.
} 
intimate. As we argued earlier, idiosyncratic decisions have to be allowed in such situations, in order to fully respect the individuals involved. These are not situations for which general social coordination is necessary, or appropriate. Of course, the best interests standard at some level coordinates the interactions of care providers, legal professionals, and families, concerning how they treat incompetent patients. But the coordination here is specific to agents within the individual cases, rather than generally across different cases. It is unlike other general forms of social coordination which we are concerned with in discussions of liberty or equality. For instance, consider decisions pertaining to punishment. In that case, we cannot have different decisions for the same cases. It would indeed be a serious flaw in the system if it were shown that radically different decisions concerning similar cases were reached. However, we may reasonably reach potentially radically different decisions for best interests cases, depending on the specifics of the cases, including the different comprehensive doctrines in play. ${ }^{17}$

Moreover, we must recognise that any "usefulness" that we may derive from socially coordinating best interests decisions would come at the hefty price of disrespecting citizens' plural views. Thus, while the worry about defeatism may be well-motivated and appropriate in situations concerning social coordination more generally, it is not easily extended to the case of best interests decisions. A clear view on the fact that the usefulness of social coordination plays an inappropriate role in best interests decisions, and may even result in the marginalisation of some citizens, should lend us enough courage to set the worry aside.

The second worry concerns our earlier remark that the state may still occupy the role of the final arbiter of disagreements concerning best interests. As the state enters to arbitrate disagreements, its decisions establish precedence which subsequently inform and influence future decisions. Eventually, they coalesce into a substantive elaboration of the best interests standard - albeit a negative one. Thus, the worry goes, the adherence to the enumerative strategy fails, for it collapses into the elaborative strategy. Here, our response is simply to insist on taking seriously our commitments to the enumerative strategy. There are two ways of doing so.

One resists the claim that state decisions simplistically establish precedence for future cases. This is motivated by our earlier discussions. A best interests decision for a Hindu patient is going to be saliently different from that of a Muslim or Christian. Additionally, this decision may differ even from that for other Hindu patients, whose affirmation of their comprehensive doctrines may be more or less fervent. Practically, this means that decisions are taken as directed only to the specific cases in concern. Where they do inform future cases, their influence should be limited to only the identification of relevant considerations. How the considerations are weighed in settled cases are not to be extended to a different context - determined, as it were, before the facts of the new context has been thoroughly considered. On this account, subsequent

\footnotetext{
${ }^{17}$ The reader may take us as advocating some limited form of casuistry for best interests decisions - which mitigates against the hand-waving in the last sentence. Unfortunately, we are unable to develop this view further here.
} 
best interests decisions would only have to be "in line with" previous decisions just to the extent that they consider and discuss relevant considerations identified earlier. This view is supported by recent court decisions,[40] and also appears implicit in Senior Judge Denzil Lush's (of the Court of Protection) proposal that we resist the temptation to bring current cases concerning best interests within other decided cases (as in common law), and that best interests decisions are unique to the cases in concern.[41] We contend that the aims of the best interests standards are best served when considerations concerning the patients and case at hand are thoroughly considered on their own, without the complications of having to bring their manner of weighing considerations, or their conclusions, in line with other dissimilar decisions in law. ${ }^{18}$

The other response consists in simply denying - in light of our earlier discussions about pluralism - that a substantive elaboration of the standard can be arrived at, which may be affirmed by all citizens from the perspectives of their comprehensive doctrines, and which can thus be fixed in law for future decisions.

\section{CONCLUSION}

We began with brief characterisations of two distinct strategies of clarifying the best interests standard, which we have observed in bioethicists' theorising. The elaborative strategy clarifies the standard by developing the content of best interests, providing guidance for how we ought to apply it across cases. The enumerative strategy restricts itself to listing all relevant considerations, without committing to any substantive conception of best interests.

We then located our subsequent discussions in terms of the question of which strategy a state in a pluralistic society may viably adopt. We thus side-stepped the issue of which strategy is better, simpliciter. A pluralistic society is characterised by its citizens having commitments to different, and often competing, comprehensive religious, moral, and philosophical doctrines - and to different degrees. This renders implausible that a general best interests standard may be formulated while fully respecting the pluralism of views concerning the best interests of incompetent patients. Thus, a state may only viable commit to the enumerative strategy.

We argued that this does not commit the state to silence in providing guidance to care providers who have to make best interests decisions, or to abuse of the vulnerable. Mechanisms and procedures may be developed and implemented, which ensure that decisions are indeed in the best interests of the patients, while remaining respectful of differences in comprehensive doctrines.

We then considered and rejected two methodological worries. The adoption of the enumerative strategy is not defeatist in attitude, insofar as there is no viable alternative. And taking seriously our commitments to the strategy, will contribute to resisting its eventual collapse into (a form of) the elaborative strategy.

\footnotetext{
${ }^{18}$ Developing and defending this account of precedence is (hopefully) the task of future work.
} 
Perhaps the best way is to understand the enumerative strategy as maintaining what Jeremy Waldron calls a 'site of thoughtfulness'.[42] Seen this way, our quest for clarity is less likely to lead us astray - to mistakenly think of the ideal best interests standard as one which we can apply mechanically across contexts, which presents us with one correct answer[43] and leaves no room for argumentation (and thus also thought), and which blinds us to the complexities and difficulties of reality.

\section{ACKNOWLEDGEMENTS}

We are grateful for the charitable and constructive comments by both the anonymous reviewers for JME, which have helped to improve this paper.

\section{COMPETING INTERESTS}

\section{REFERENCES}

1. Buchanan A, Brock DW. Deciding for Others. Milbank Q 1986;64(2):1794.

2. Dunn MC, Clare IC, Holland AJ. Living 'A life like ours': Support workers' accounts of substitute decision-making in residential care homes for adults with intellectual disabilities. J Intellect Disabil Res 2010;54: $144-160$

3. Archard D, Skivenes, M. Balancing a child's best interests and a child's views. International Journal of Children's Rights 2009;17:1-21

4. Dunn MC, Clare ICH, Holland AJ et al. Constructing and reconstructing 'best interests': An interpretative examination of substitute decisionmaking under the Mental Capacity Act 2005, J Soc Welf Fam Law 2007;29(2):117-133.

5. Coggon J and Holm S.Best interests: A reappraisal. Health Care Anal 2008;16(3):193-196

6. Coggon J.Best interests, public interest, and the power of the medical profession, Health Care Anal 2008;16(3):219-232

7. McGuinness S. Best interests and pragmatism. Health Care Anal 2008;16(3):208-218

8. Brody H, Bartholome W. Contested terrain: In the best interests of... Hastings Cent Rep 1988;18(6):37-40

9. Cantor N. Making Medical Decisions for the Profoundly Mentally Disabled. Cambridge: MIT Press 2005.

10. Superintendent of Belchertown State School v. Saikewicz, 373 Mass. 728, 370 N.E.2d 417 (1977).

11. W v M and others [2011] EWHC 2443 (Fam).

12. The National Archives. United Kingdom Mental Capacity Act 2005. Available at http://www.legislation.gov.uk/ukpga/2005/9/contents [Accessed 1 February 2016].

13. Singapore Statutes Online. Singapore Mental Capacity Act 2008. Available at http://statutes.agc.gov.sg/aol/search/display/view.w3p;query=DocId\%3A7 f933c47-8a34-47d1-8d0a0a457d6fa1c2\%20\%20Status\%3Ainforce\%20Depth\%3A0;rec=0; whole=y es [Accessed 1 February 2016]. 
14. Department for Constitutional Affairs. Mental Capacity Act 2005: Code of Practice. London: The Stationary Office 2007.

15. Office of the Public Guardian. Code of Practice: Mental Capacity Act. Singapore: Office of the Public Guardian 2015.

16. Rawls J. Political Liberalism. New York: Columbia University Press 1993.

17. Degrazia D. Value theory and the best interests standard. Bioethics 1995;9(1):50-61.

18. Freeman M. Culture, childhood and rights, The Family in Law 2011; 5(15):15-33.

19. Hope T, Slowther A, Eccles J. Best interests, dementia and the Mental Capacity Act (2005). J Med Ethics 2009;35(12):733-738.

20. Hawkins J. Well-being, time, and dementia. Ethics 2014;124(3):507-542.

21. Fenwick A. Applying best interests to persistent vegetative state - a principled distortion? J Med Ethics 1999;24(2):86-92.

22. Huxtable R. Law, Ethics and Compromise at the Limits of Life: To Treat or Not To Treat? Oxon: Routledge 2013.

23. Beauchamp T, Childress J. Principles of Biomedical Ethics, 5th Edition. Oxford: Oxford University Press 2001.

24. Baily S. In whose interests? The best interests principle under ethical scrutiny. Aust Crit Care 2001;14(4):161-164.

25. Kilan B. John Rawls' idea of an 'overlapping consensus' and the complexity of comprehensive doctrines. Ethical Perspect 2009;16(1):2160.

26. Rid A, Wendler D. Use of a patient preference predictor to help make medical decisions for incapacitated patients, J Med Philos 2014;39(2):104129

27. Wendler D, Wesley B, Pavlick M and Rid A. A new method for making treatment decisions for incapacitated patients: What do patients think about the use of a patient preference predictor? J Med Ethics. Online First. Available at: http://jme.bmj.com/content/early/2016/01/29/medethics2015-103001. [Accessed 1 February 2016].

28. Kirby J. Balancing legitimate critical-care interests: setting defensible care limits through policy development. Am J Bioeth 2016;16(1):38-47.

29. Birmingham Children's NHS Trust v B \& C [2014] EWHC 531 (Fam).

30. M Children’s Hospital NHS Foundation Trust v Mr \& Mrs Y [2014] EWHC 2651 (Fam).

31. NHS v Child B, Mr and Mrs B [2014] EWHC 3486 (Fam).

32. University Hospital Southampton, National Health Service. 2014. Young persons refusing blood transfusion. Available at http://www.uhs.nhs.uk/HealthProfessionals/Clinical-law-updates/Youngperson-refusing-blood-transfusion.aspx. [Accessed 1 February 2016].

33. Kitzinger J, Kitzinger C. Court applications for withdrawal of artificial nutrition and hydration from patients in a permanent vegetative state: Family experiences. J Med Ethics 2016;42(1):11-17.

34. The Guardian, 6 November 2011, 'The Court of Protection: Defender of the vulnerable or shadowy and unjust?' Available http://www.theguardian.com/law/2011/nov/06/court-protection-defendervulnerable-unjust [Accessed 1 February 2016].

35. Foner E. The Story of American Freedom. New York: W. W. Norton \& Company Ltd 1999. 
36. Nussbaum M. Human capabilities, female human beings. In: Nussbaum M, Glover J, eds. Women, Culture, and Development: A Study of Human Capabilities. Oxford: Oxford University Press 1995: 61-104.

37. Nussbaum M. Capabilities and Disabilities: Justice for Mentally Disabled Citizens. Philosophical Topics 2002;30(2):133-165

38. Kleist C. Global ethics: Capabilities approach. Internet Encyclopedia of Philosophy 2010. Available at http://www.iep.utm.edu/ge-capab/ [Accessed 1 February 2016].

39. Jaggar A. Reasoning about well-being: Nussbaum's methods of justifying the capabilities. J Polit Philos 2006;14(3):301-322.

40. Re M, ITW V Z and others [2009] EWHC 525 (Fam)

41. Singapore Law Gazette. Mental Capacity Act - A new framework. Available at http://www.lawgazette.com.sg/2010-05/feature2.htm [Accessed 1 February 2016].

42. Waldron J. What do philosophers have against dignity? Public Law \& Legal Theory Research Paper Series 2014;14(59):1-22.

43. Sokol D. Ethics man: Clarifying best interests. Br Med J 2008;337(7664):264. 